\title{
Very High Third-Order Nonlinear Optical Activities of Intrazeolite PbS Quantum Dots
}

\section{Supporting Information}

\section{SI-1. Preparation of $\mathbf{Y}_{\mathrm{g}} \mathrm{S}$}

The $\mathrm{Y}_{\mathrm{g}} \mathrm{s}\left(2 \times 2.5 \mathrm{~cm}^{2}\right)$ were prepared according to the procedure described in our previous report (ref 21 in the text, Jeong, N. C.; Kim, H. S.; Yoon, K. B. Langmuir 2005, 21, 6038.) using ITO glass plates instead of ordinary glass plates. The average thickness of the pristine zeolite-Y films was $2.0 \mu \mathrm{m}$. After polishing them with a piece of fine cloth and alumina powders $(0.3 \mu \mathrm{m})$, the pristine, opaque zeolite $\mathrm{Y}$ films became transparent and the average thickness decreased to $1.5 \mu \mathrm{m}$.

\section{SI-2. SEM and photographic images of Zeolite-Y films}
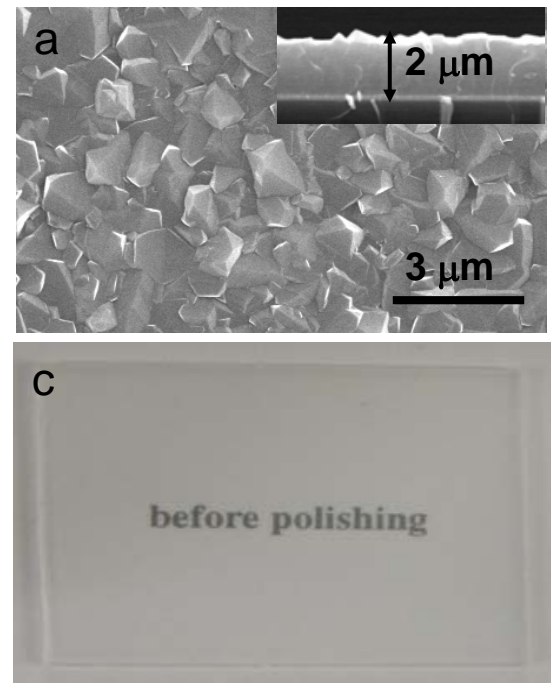
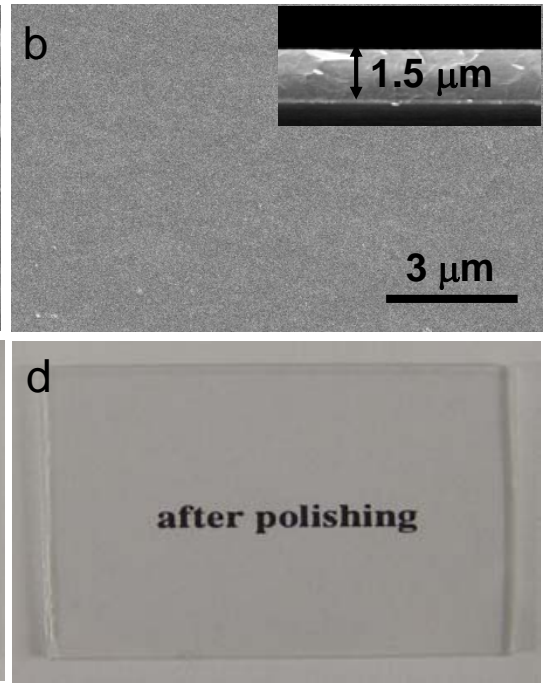

Figure. SEM images (top views) of zeolite-Y films grown on ITO glass plates ( $\left.\mathrm{Y}_{\mathrm{g}} \mathrm{s}\right)$ before (a) and after (b) polishing and the photographs of an $\mathrm{Y}_{\mathrm{g}}$ before (c) and after (d) polishing. The SEM images in the insets of (a) and (b) show the corresponding cross sections. 


\section{SI-3. Preparation of $(\mathrm{PbS})_{\mathrm{n}}$-intercalating $\mathbf{Y}_{\mathrm{g}} \mathrm{s}\left[(\mathrm{PbS})_{\mathrm{n}}-\mathrm{Y}_{\mathrm{g}}\right]$}

An $\mathrm{Y}_{\mathrm{g}}$ (zeolite-Y film grown on ITO glass) plate was immersed into each $25-\mathrm{mL}$ aliquot of $\mathrm{Pb}\left(\mathrm{NO}_{3}\right)_{2}$ solutions of different concentrations ( $\mathrm{xMM}, \mathrm{x}=0.1,0.4,1$, and 10) for $30 \mathrm{~min}$ at room temperature. The removed $\mathrm{Pb}^{2+}$-exchanged $\mathrm{Y}_{\mathrm{g}}\left[(\mathrm{Pb})-\mathrm{Y}_{\mathrm{g}}\right]$ was washed with copious amounts of distilled deionized water, and dried by blowing nitrogen onto the film. The amount of $\mathrm{Pb}^{2+}$ ions per unit cell in each $(\mathrm{Pb})-\mathrm{Y}_{\mathrm{g}}$ was $8,14,23$, and 33 , respectively. The $(\mathrm{Pb})-\mathrm{Y}_{\mathrm{gS}}$ were then introduced into a Schlenk tube and then dried at $200{ }^{\circ} \mathrm{C}$ for $12 \mathrm{~h}$ under vacuum (< $10^{-5}$ Torr). Dry $\mathrm{H}_{2} \mathrm{~S}$ gas (Rigas, 99.5\%) was introduced into the Schlenk tube containing dry $(\mathrm{Pb})-\mathrm{Y}_{\mathrm{g}}$ plates at room temperature. After allowing them to react with dry $\mathrm{H}_{2} \mathrm{~S}$ for $1 \mathrm{~h}$, excess $\mathrm{H}_{2} \mathrm{~S}$ gas was removed by evacuation of the Schlenk tube for $10 \mathrm{~min}$ at room temperature. The compositions were analyzed by both energy dispersive X-ray spectroscopy (EDX) and chemical elemental analyses. 
SI-4. TEM images of bare zeolite-Y crystals (A), ODM-(PbS) $)_{33}-\mathrm{Y}$ crystals (B), and moist$(\mathrm{PbS})_{33}-\mathrm{Y}$ crystals $(\mathrm{C})$ at different magnifications (as indicated).

A. Bare zeolite-Y crystals

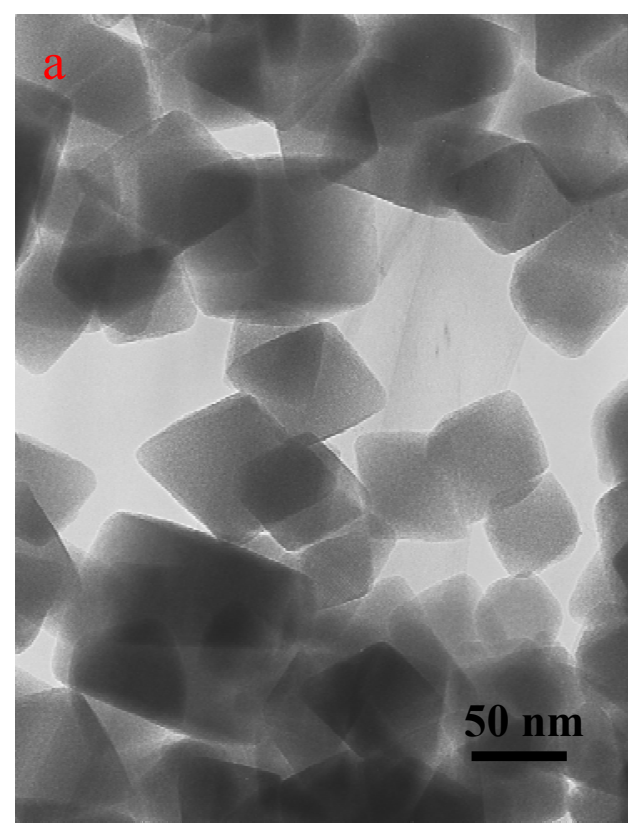

B. ODM-(PbS) $)_{33}-\mathrm{Y}$ crystals

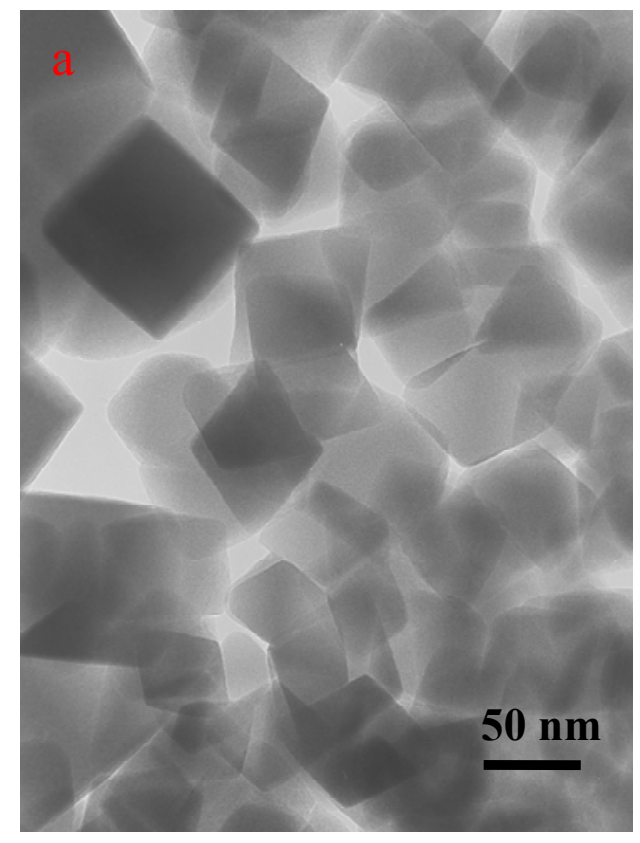

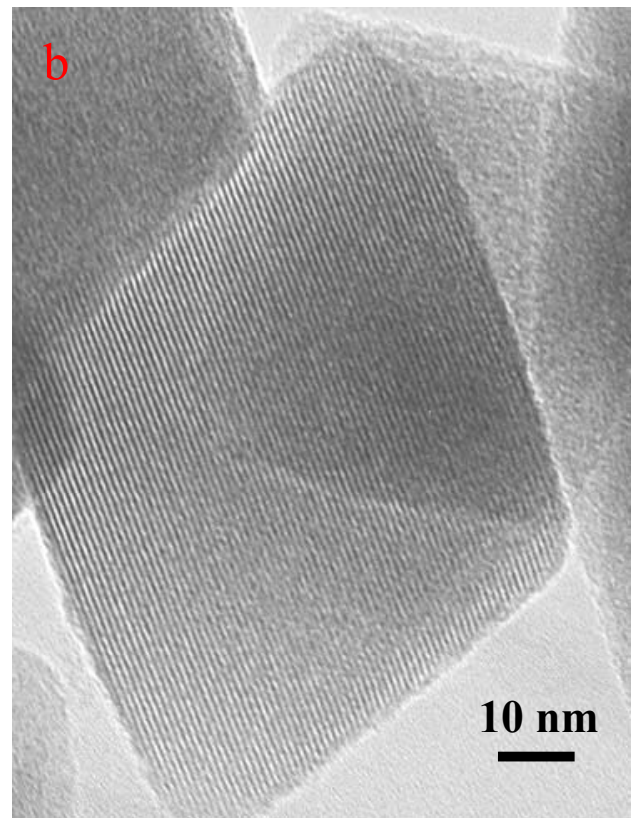

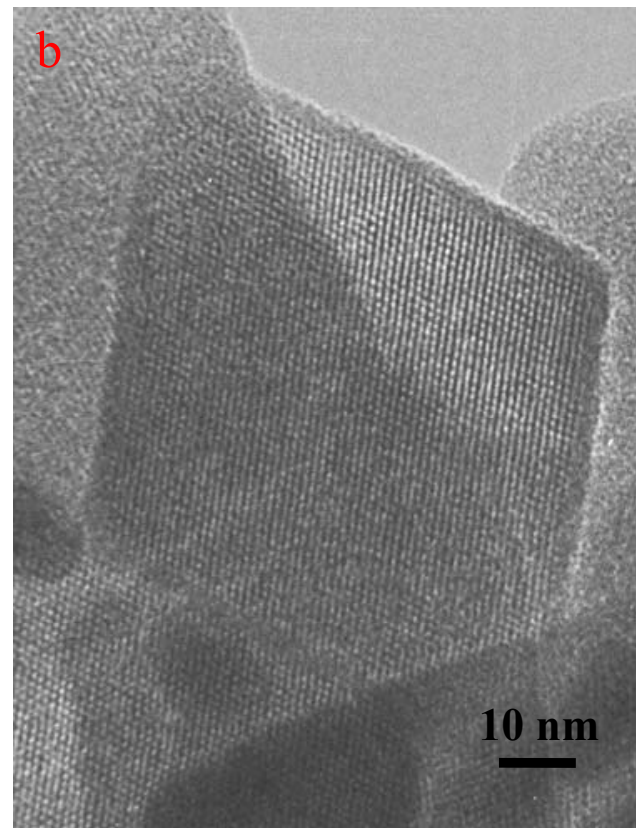




\section{C. moist-(PbS) $)_{33}$-Y crystals}
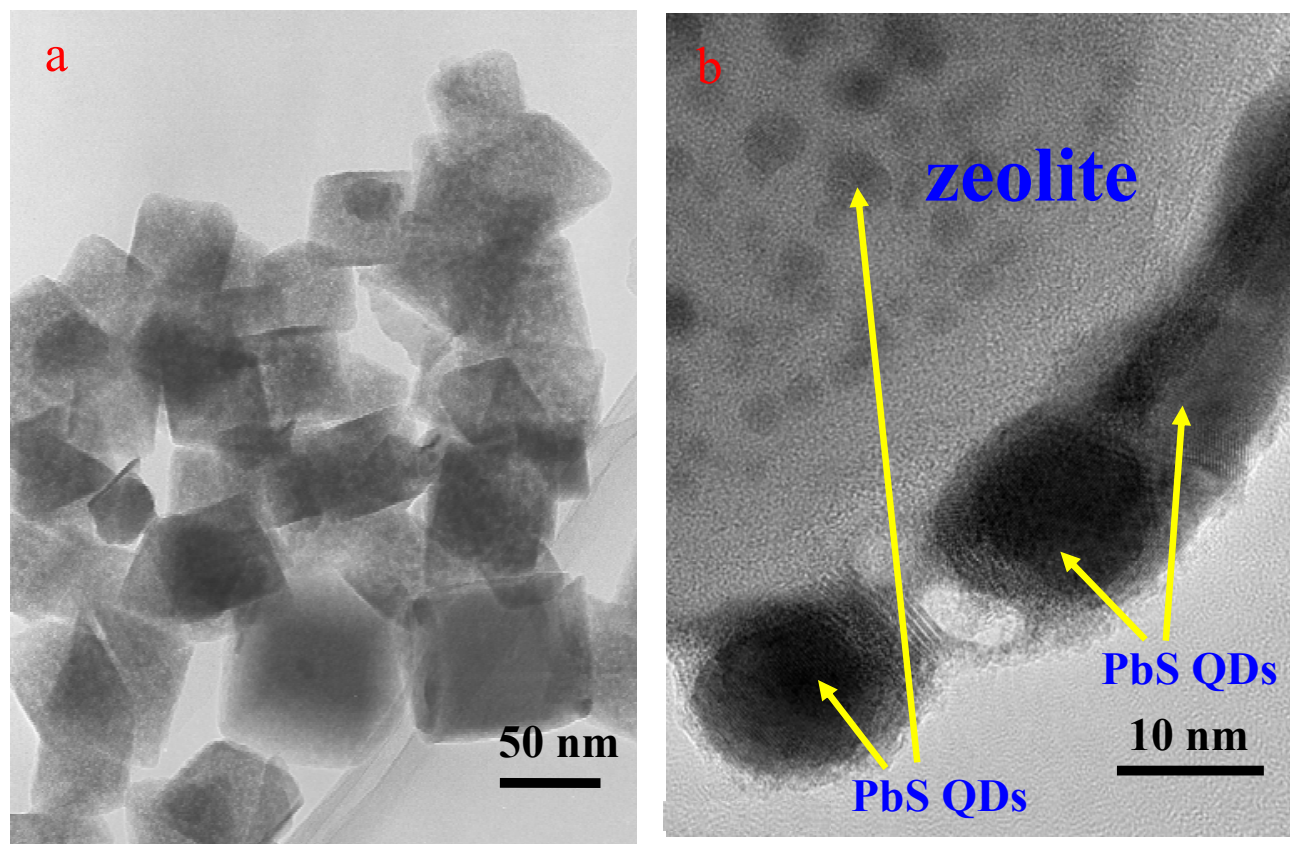

For the ease of TEM analyses, we used zeolite-Y crystals [bare zeolite Y crystals, ODM-coated $(\mathrm{PbS})_{33}$-containing zeolite-Y, and moisture-adsorbed $(\mathrm{PbS})_{33}$-containing zeolite-Y crystals] instead of bare $\mathrm{Y}_{\mathrm{g}}, \mathrm{ODM}-(\mathrm{PbS})_{33}-\mathrm{Y}$, and moist- $(\mathrm{PbS})_{33}-\mathrm{Y}$. The zeolite crystals were those that were obtained from the gel which was used for the growth of $Y_{\mathrm{g}}$. (They were from the same batch.) Therefore, the $\mathrm{Si} / \mathrm{Al}$ ratios of the above zeolite-Y crystals and $\mathrm{Y}_{\mathrm{g}}$ (zeolite-Y films supported on glass) were nearly the same. Zeolite-Y crystals: $\mathrm{Si} / \mathrm{Al}=1.86$, zeolite-Y films: $\mathrm{Si} / \mathrm{Al}$ ratio $=1.81$.

A. TEM images showing the high crystallinity of bare zeolite-Y crystals.

B. TEM images showing that the crystallinity of most of the zeolite- $Y$ crystals were preserved even after production of $\mathrm{PbS}$ QDs within the pores, despite the fact that protons $\left(\mathrm{H}^{+}\right)$were simultaneously generated within the pores, and after coating the surface with ODM. In this case, although there are PbS QDs within the zeoltie crystals, they are not detectable in the above images, indicating that their sizes are smaller than $1.5 \mathrm{~nm}$.

C. TEM images showing the clear evidence that large PbS QDs $(3-20 \mathrm{~nm})$ appear on the surfaces of zeolite-Y upon adsorption of moisture into $(\mathrm{PbS})_{33}-\mathrm{Y}$. Note that the images in $\mathrm{B}$ are clearly different from those in $\mathrm{C}$. 


\section{SI-5. Surface silylation.}

Dry $(\mathrm{PbS})_{\mathrm{n}}-\mathrm{Y}_{\mathrm{gS}}$ were transferred into a dry box charged with high purity argon and then placed on a Teflon support. The support was immersed into a hexane solution of ODM consisting of $10 \mathrm{~mL}$ of ODM and $90 \mathrm{~mL}$ of hexane contained in a glass chamber. The chamber with a lid on was placed for $1 \mathrm{~h}$ on a hot plate whose temperature was maintained at $60{ }^{\circ} \mathrm{C}$. After cooling the mixture to ambient temperature, the ODM-coated samples were washed with copious amounts of dry $n$-hexane.

\section{SI-6. ${ }^{27} \mathrm{AI}$ NMR and ${ }^{29} \mathrm{Si}$ NMR spectra of bare zeolite $\mathrm{Y}$ crystals, $(\mathrm{Pb})_{33}$-exchanged zeolite- $\mathrm{Y}$, ODM-coated $(\mathrm{PbS})_{33}$-containing zeolite-Y, and moisture-adsorbed $(\mathrm{PbS})_{33}$-containing zeolite-Y crystals}
A. ${ }^{27}$ Al NMR Spectra
B. ${ }^{29}$ Si NMR Spectra
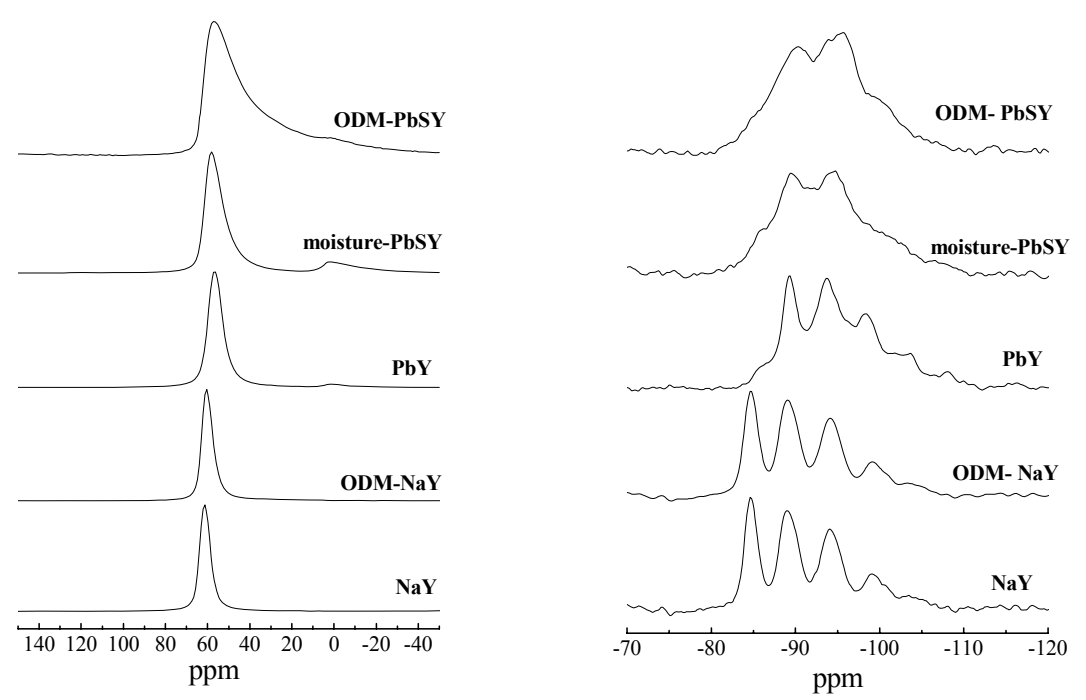

A. The ${ }^{27} \mathrm{Al}$ NMR spectra of bare NaY and ODM-coated NaY are the same, indicating that the ODM-coating does not affect the crystallinity of the zeolite. However, $(\mathrm{Pb})_{33} \mathrm{Y}$ shows slight line broadening of the resonance at $57 \mathrm{ppm}$, due to tetrahedrally coordinated $\mathrm{Al}$ atoms, accompanying the simultaneous appearance of a resonance at $0 \mathrm{ppm}$, due to octahedrally coordinated $\mathrm{Al}$ ions, indicating partial framework rupture. Moisture-adsorbed $(\mathrm{PbS})_{33^{-}}$ containing zeolite-Y crystals show that the resonance at $57 \mathrm{ppm}$ is broadened a bit more and 
the intensity of the 0 -ppm peak increased a bit more, indicating that the partial framework rupture progressed a bit more during the moisture-induced formation of $\mathrm{PbS}$ crystals on the surface (see SI-4). However, this shows that the most part of the structure is preserved during the above process. The line broadening of 60 -ppm resonance peak underwent even further upon coating the surfaces of dry $(\mathrm{PbS})_{33}$-containing zeolite-Y crystals with ODM. Since the TEM images of the zeolite crystals (SI-5) showed that the overall crystallinity of the crystals were preserved, the above ${ }^{27} \mathrm{Al}$ NMR spectrum indicates that partial rupture of the internal frameworks underwent during ODM coating.

B. The ${ }^{29} \mathrm{Si} \mathrm{NMR}$ spectra of bare $\mathrm{NaY}$ and ODM-coated $\mathrm{NaY}$ are the same, indicating that the ODM-coating does not affect the crystallinity of the zeolite. However, in the case of $(\mathrm{Pb})_{33} \mathrm{Y}$, the intensity of the $\mathrm{Q}_{4}$ peak decreased accompanying the broadening of other peaks. In the cases of moisture-adsorbed $(\mathrm{PbS})_{33}$-containing zeolite- $\mathrm{Y}$ and ODM-coated $(\mathrm{PbS})_{33}$-containing zeolite-Y crystals, the degree of line broadening increased even further. Coupled with the fact that the TEM images of the above zeolite crystals (SI-5) showed that their overall crystallinity was preserved, the above NMR spectra indicate that the internal frameworks underwent partial rupture during $\mathrm{PbS}$ QD generation.

\section{SI-7. X-ray diffraction patterns of bare zeolite-Y crystals, $(\mathrm{Pb})_{33}$-exchanged zeolite-Y, ODM-coated $(\mathrm{PbS})_{33}$-containing zeolite-Y, and moisture-adsorbed $(\mathrm{PbS})_{33}$-containing zeolite-Y crystals}

To check the crystallinity of zeolite Y during the preparation of PbS QDs within the pores, we also prepared zeolite-Y crystals from the same synthesis gel which was used for the synthesis of zeolite Y films on ITO glass. The composition of the gel was $14 \mathrm{Na}_{2} \mathrm{O}: \mathrm{Al}_{2} \mathrm{O}_{3}: 10 \mathrm{SiO}_{2}: 720 \mathrm{H}_{2} \mathrm{O}$. The crystallization was carried out at $100{ }^{\circ} \mathrm{C}$ for $15 \mathrm{~h}$. The average particle size of the crystals was $0.8 \mu \mathrm{m}$.

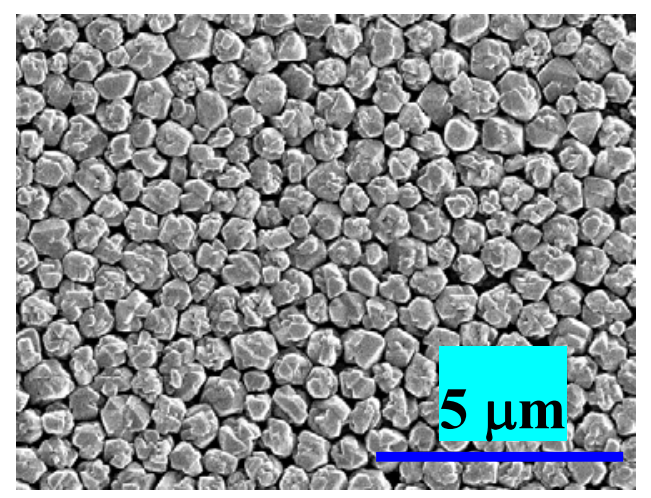


The X-ray powder diffraction patterns were obtained from Rigaku diffractometer (D/MAX-1C) with the monochromatic beam of $\mathrm{Cu} \mathrm{K \alpha}$.

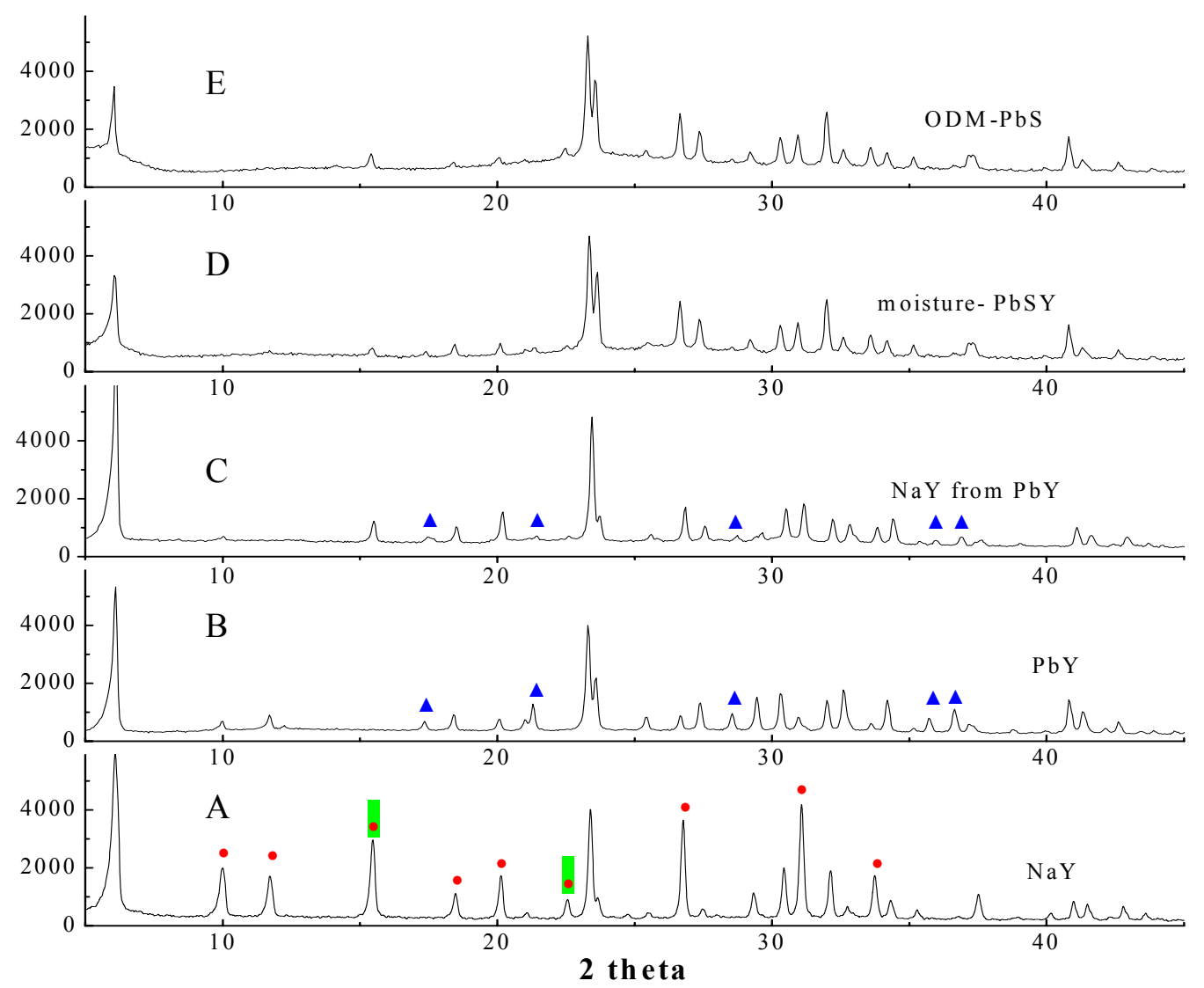

$\mathrm{X}$-ray powder diffraction pattern of bare $\mathrm{Na}^{+}$-exchanged zeolite-Y (NaY) crystals (panel A) confirmed their structure (zeolite-Y). The diffraction pattern of $(\mathrm{Pb})_{33}$-exchanged zeolite-Y (panel B) was different from that of $\mathrm{NaY}$. For instance, the peaks in $\mathrm{NaY}$ (panel A) marked with a red dot in a green rectangle $(\bullet)$ disappeared and the peaks marked with a red dot (•) significantly decreased while the peaks marked with a blue triangle ( $\mathbf{\Delta})$ newly appeared (panel B). Since the newly appeared small peaks did not disappear even after re-exchange of $\mathrm{Pb}^{2+}$ ions with $\mathrm{Na}^{+}$ions (panel $\mathrm{C}$ ), we conclude that the small peaks appeared due to partial framework rupture during ion exchange of $\mathrm{Na}^{+}$ions with $\mathrm{Pb}^{2+}$ ions and ruptured frameworks do not restore back to the original structure even after re-exchange of $\mathrm{Pb}^{2+}$ ions with $\mathrm{Na}^{+}$ions. The intensities of the diffraction patterns of moisture-adsorbed $(\mathrm{PbS})_{33}$-containing zeolite-Y crystals (panel $\mathrm{D}$ ) and ODM-coated $(\mathrm{PbS})_{33}$-containing zeolite-Y (panle E) decreased a bit indicating that the crystals underwent minor internal framework rupture during generation of $\mathrm{PbS}$. 


\section{SI-8. Verification of the existence of PbS QDs within zeolite-Y.}

For the above we obtained the compositions of $(\mathrm{PbS})_{\mathrm{n}}-\mathrm{Y}_{\mathrm{g}}$ samples. The results are summarized in the following table.

Table. Compositions of $(\mathrm{PbS})_{\mathrm{n}}-\mathrm{Y}_{\mathrm{g}}$.

\begin{tabular}{ll}
\hline zeolite film & composition \\
\hline ODM- $\left[(\mathrm{PbS})_{0}\right]-\mathrm{Y}_{\mathrm{f}}$ & $\mathrm{Na}_{70.2} \mathrm{Al}_{70.3} \mathrm{Si}_{121.7} \mathrm{O}_{384}$ \\
ODM- $\left[(\mathrm{PbS})_{8}\right]-\mathrm{Y}_{\mathrm{f}}$ & $\mathbf{P b}_{7.9} \mathbf{S}_{7.2} \mathrm{H}_{14.4} \mathrm{Na}_{54.5} \mathrm{Al}_{70.3} \mathrm{Si}_{121.7} \mathrm{O}_{384}$ \\
ODM- $\left[(\mathrm{PbS})_{14}\right]-\mathrm{Y}_{\mathrm{f}}$ & $\mathbf{P b}_{14.4} \mathbf{S}_{14.1} \mathrm{H}_{28.2} \mathrm{Na}_{41.5} \mathrm{Al}_{70.3} \mathrm{Si}_{121.7} \mathrm{O}_{384}$ \\
ODM- $\left[(\mathrm{PbS})_{23}\right]-\mathrm{Y}_{\mathrm{f}}$ & $\mathbf{P b}_{22.9} \mathbf{S}_{22.3} \mathrm{H}_{44.6} \mathrm{Na}_{24.5} \mathrm{Al}_{70.3} \mathrm{Si}_{121.7} \mathrm{O}_{384}$ \\
ODM- $\left[(\mathrm{PbS})_{33}\right]-\mathrm{Y}_{\mathrm{f}}$ & $\mathbf{P b}_{33.4} \mathbf{S}_{33.0} \mathrm{H}_{66.0} \mathrm{Na}_{3.5} \mathrm{Al}_{70.3} \mathrm{Si}_{121.7} \mathrm{O}_{384}$ \\
moist- $\left[(\mathrm{PbS})_{33}\right]-\mathrm{Y}_{\mathrm{f}}$ & $\mathbf{P b}_{33.4} \mathbf{S}_{33.0} \mathrm{H}_{66.0} \mathrm{Na}_{3.5} \mathrm{Al}_{70.3} \mathrm{Si}_{121.7} \mathrm{O}_{384} \cdot \mathrm{xH}_{2} \mathrm{O}$ \\
\hline
\end{tabular}

The above compositions were obtained by both energy dispersive X-ray spectroscopy (EDX) analyses and chemical elemental analyses. (The chemical analyses were conducted with the zeolite films that were scraped from the glass substrates.) Both results coincided within the experimental errors.

The above elemental analyses clearly showed the 1:1 ratio of both elements $(\mathrm{Pb}$ and $\mathrm{S})$ in each zeolite. From the fact that PbS QDs do not exist on the external surface (see SI-4), we conclude that PbS QDs indeed exist within the zeolite frameworks. The existence of ObS QDs within zeolite-Y was also verified by ref 13 in the main text.

The spectra of $(\mathrm{PbS})_{\mathrm{n}}-\mathrm{Y}_{\mathrm{g}}$ (Figure 1, right) did not show the exciton absorption bands. We propose the following two reasons are responsible for the above phenomenon.

1) The sizes of QDs are not uniform. We believe that the sizes of PbS QDs vary from subnanometer to $\sim 1.5 \mathrm{~nm}$ depending on the number of $\mathrm{PbS}$ unit in each QD. Thus, the juxtaposition of many exciton bands at different wavelengths will produce the absorption spectra having no specific envelopes.

2) In the case of $\mathrm{PbS} \mathrm{QDs}$ surrounded by anionic centers such as $\mathrm{CO}_{2}{ }^{-}$or $\mathrm{SO}_{3}{ }^{-}$the excitonic bands have not been observed despite the fact that the sizes of the PbS QDs were fairly uniform (ref 12 in the main text). Since the zeolite-Y framework is also negatively charged, such an electric field effect may appear in their spectra. 


\section{SI-9. Measurements of $\gamma$ and $\beta$ values by the Z-scan method.}

The $\gamma$ and $\beta$ values of the samples were obtained by z-scan technique at 532 and $1064 \mathrm{~nm}$, respectively, using a mode-locked Nd:YAG laser of 50-ps pulse duration with the repetition rate of $10 \mathrm{~Hz}$. The layout of z-scan method used in this work is as follows.

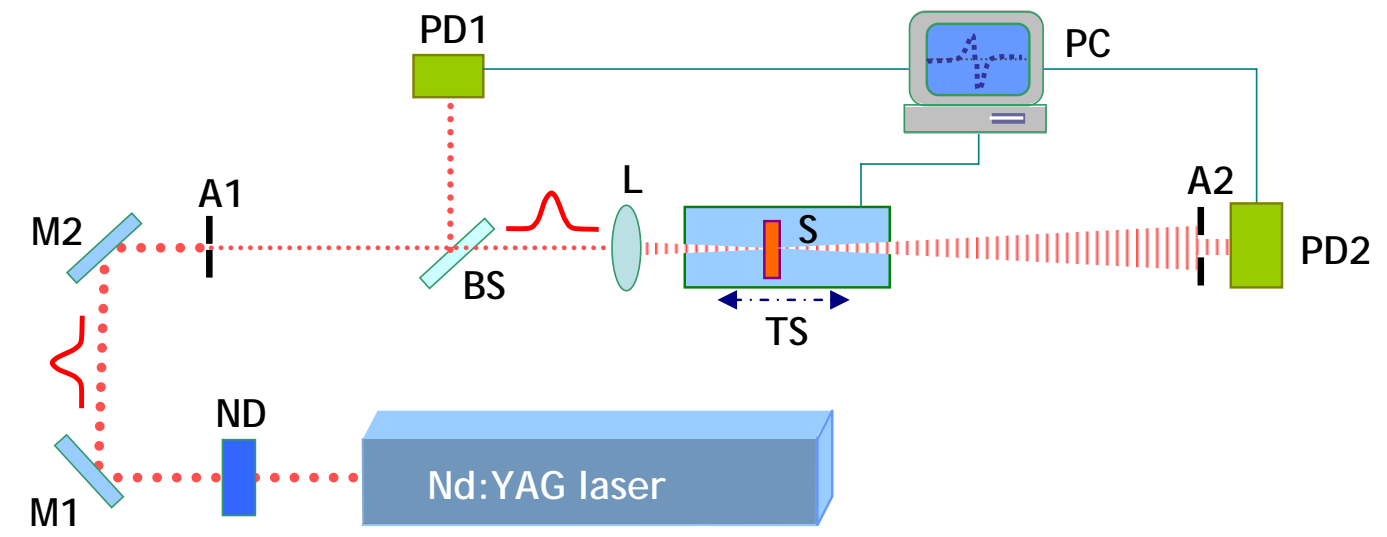

The layout of z-scan method used in this work.

ND: a neutral-density filter for the attenuation of beam power

M1, M2: highly reflecting mirrors for 532 and $1064 \mathrm{~nm}$

A1: (an iris diaphragm) an aperture

A2: (an iris diaphragm) an aperture used only for the closed-aperture Z-scan measurement

BS: a beam splitter

L: a focusing lens with the focal length of $20 \mathrm{~cm}$

S: a sample

TS: a motorized linear translational stage controlled by a PC

PD1: a photodiode for data acquisition of the triggered pulses

PD2: a photodiode for data acquisition of the signal pulses

The laser beam was split into two parts $(\sim 40 \%$ and $\sim 60 \%)$ using a beam splitter. A part $(\sim 40 \%)$ of the beam was used to compensate the intensity fluctuation of individual laser pulses. The other part ( $\sim 60 \%)$ was focused using a convex lens (focal length $=20 \mathrm{~cm}$ ) and directed to the sample. The sample was placed on a stepping-motor-driven translational stage which can traverse along the on-axis of the focused beam in a unit interval of $1 \mathrm{~mm}$. The intensity of the transmitted beam was measured using a Si photodiode (PIN-10D, UDT sensors). In the case of open-aperture z-scan, the whole energy of the transmitted beam was measured. In the case of 
on-axis (closed-aperture) z-scan measurement, an iris was placed in front of the detector. To satisfy the criteria for the on-axis transmittance, the diameter of the iris aperture was made to be $2 \mathrm{~mm}$ so that only $1 \%$ of the transmitted beam was collected by the detector. The input irradiance at the focal point $\left(\mathrm{I}_{0}\right)$ was 0.10 and $0.18 \mathrm{GW} / \mathrm{cm}^{2}$ at $532 \mathrm{~nm}$ and 0.27 and 0.47 $\mathrm{GW} / \mathrm{cm}^{2}$ at $1064 \mathrm{~nm}$.

\section{SI-10.}

The relaxation time was measured using the pump-probe set up shown below.

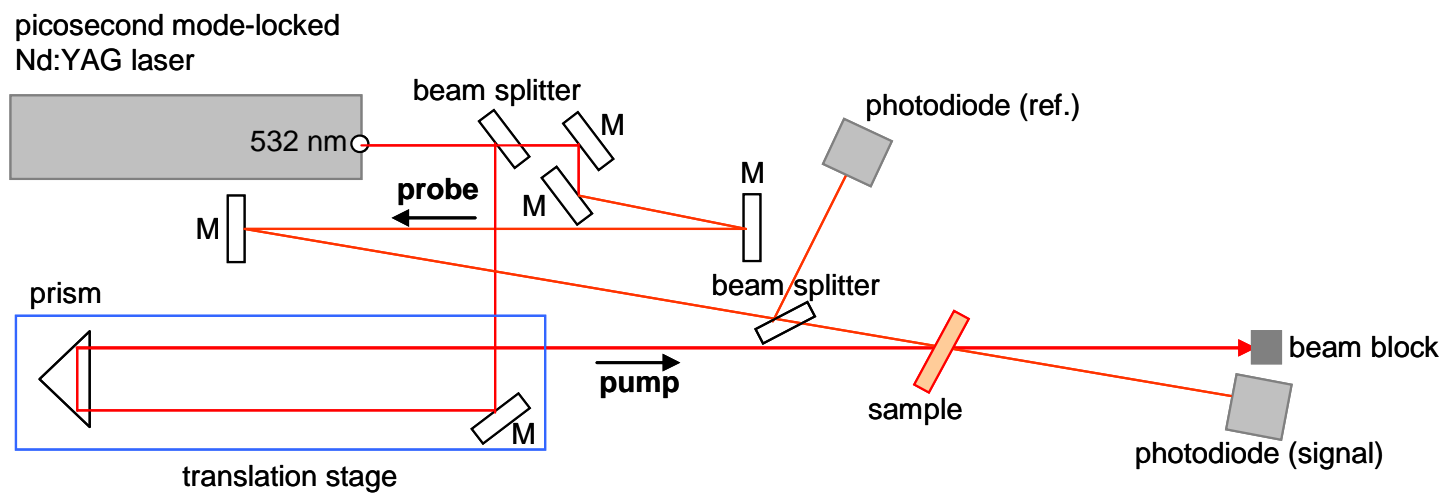

. The typical result is shown below.

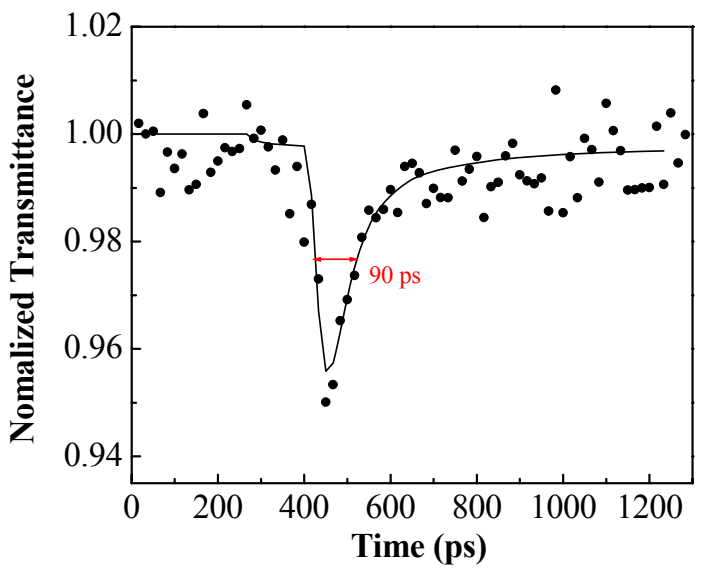




\section{SI-11. The estimated $\gamma / \alpha_{o}$ of reference 11.}

The $\gamma$ values of silica-titania sol-gel films (thickness $1 \mu \mathrm{m}$ ) doped with various amounts of $\mathrm{PbS}$ quantum dots were measured by Martucci et al. (ref 11) using ns and ps laser pulses. Among them the largest $\gamma$ value was obtained from $25 \%$-loaded sample. The $\gamma$ value obtained from $25 \%$-loaded sample under the condition that is similar to our case (using picosecond laser pulses with the pulse width of $60 \mathrm{ps}$ and $10 \mathrm{~Hz}$ repetition rate) at $1064 \mathrm{~nm}$ was $-2 \times 10^{-12} \mathrm{~cm}^{2} /$ W. Since the authors did not report the absorbance at $1064 \mathrm{~nm}$, we estimated the absorbance from Figure 3 shown below. The estimated absorbance $\left(\alpha_{0}\right)$ of the $25 \%$ sample was 0.04 . Accordingly, the estimated $\gamma / \alpha_{0}$ was $-5 \times 10^{-15} \mathrm{~cm}^{2} / \mathrm{W} \cdot \mathrm{cm}$

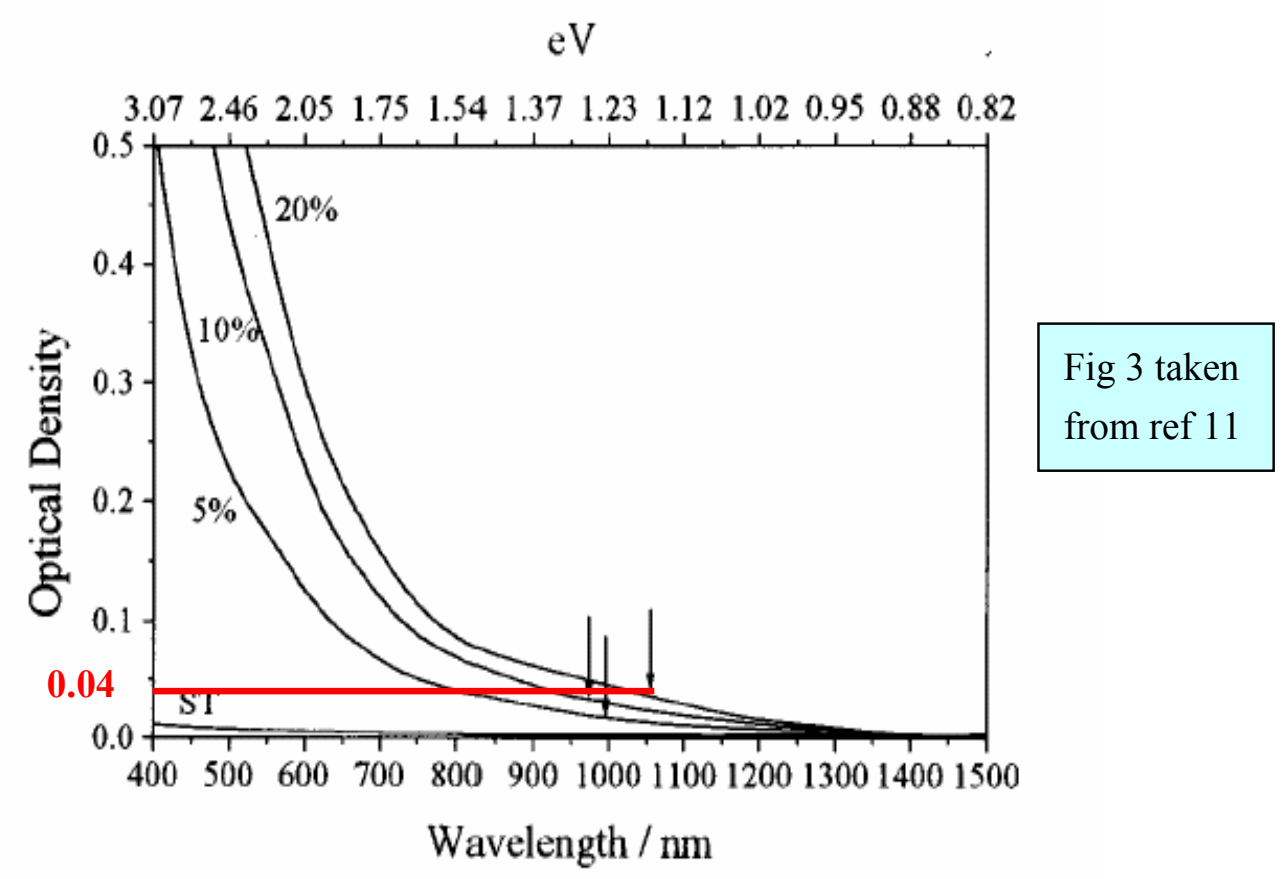

FIG. 3. Absorption spectra of $\mathrm{SiO}_{2}-\mathrm{TiO}_{2}$ film doped with 5,10 , and 25 $\mathrm{mol} \%$ of $\mathrm{PbS}$. The spectrum of an undoped film (ST) is also reported as reference. The arrows indicate the expected position of the first excitonic peak for particles with the mean diameter reported in Table II and estimated by XRD measurements.

Interestingly, however, the $\%$ in the caption and the spectra are different. Thus while it is $20 \%$ in the figure, it is $25 \%$ in the caption. Therefore, the actual absorbance of $25 \%$ sample should be higher. If this is the case, the $\gamma / \alpha_{o}$ should be smaller than $-5 \times 10^{-15} \mathrm{~cm}^{2} / \mathrm{W} \cdot \mathrm{cm}$. Note that the $\gamma / \alpha_{\mathrm{o}}$ from ODM-(PbS) $)_{33}-\mathrm{Y}_{\mathrm{g}}$ in our result $\left(-2.8 \times 10^{-13} \mathrm{~cm}^{2} / \mathrm{W} \cdot \mathrm{cm}\right.$ at $1064 \mathrm{~nm}$.) is larger by 56 times than the value observed from silica-titania sol-gel film doped with 25\% PbS QDs. 